\title{
Comparison of Two Preparation Methods on Catalytic Activity and Selectivity of Ru-Mo/HZSM5 for Methane Dehydroaromatization
}

\author{
Lucia M. Petkovic and Daniel M. Ginosar \\ Idaho National Laboratory, Idaho Falls, ID 83415-3632, USA \\ Correspondence should be addressed to Lucia M. Petkovic; lucia.petkovic@inl.gov
}

Received 1 May 2014; Accepted 12 June 2014; Published 2 July 2014

Academic Editor: Marcello De Falco

Copyright (C) 2014 L. M. Petkovic and D. M. Ginosar. This is an open access article distributed under the Creative Commons Attribution License, which permits unrestricted use, distribution, and reproduction in any medium, provided the original work is properly cited.

\begin{abstract}
Catalytic performance of Mo/HZSM5 and Ru-Mo/HZSM5 catalysts prepared by vaporization-deposition of molybdenum trioxide and impregnation with ammonium heptamolybdate was analyzed in terms of catalyst activity and selectivity, nitrogen physisorption analyses, temperature-programmed oxidation of carbonaceous residues, and temperature-programmed reduction. Vaporizationdeposition rendered the catalyst more selective to ethylene and coke than the catalyst prepared by impregnation. This result was assigned to lower interaction of molybdenum carbide with the zeolite acidic sites.
\end{abstract}

\section{Introduction}

Catalytic methane dehydroaromatization is a potential alternative to methane steam reforming to produce hydrogen. It is also an alternative for production of valuable aromatics from oil-associated gases that are usually flared. Since its first report in 1993 [1], however, methane dehydroaromatization continues to be a challenge from both scientific (nature of catalyst active sites) and industrial (catalyst activity and stability) points of view [1-9]. The most promising catalyst is Mo/HZSM5 [1, 10-13]. Dehydroaromatization of methane on Mo-zeolite catalysts has been proposed to follow an initial induction period during which $\mathrm{Mo}$ is reduced to molybdenum carbide $\left(\mathrm{MoC}_{x}\right)$. Methane activation occurs on $\mathrm{MoC}_{x}$ which leads to the formation of ethylene and hydrogen. Ethylene then reacts on the zeolite acidic sites to form aromatics $[14,15]$. The acid sites and channel structure of the zeolite and the state and location of Mo species are fundamental factors for good catalytic performance [16].

A number of different preparation methods and incorporation of different promoters have been reported [10, 17, 18]. In particular, Weckhuysen et al. [10] reported that the incorporation of molybdenum onto the HZSM5 zeolite by impregnation produced a catalyst that displayed higher activity and shorter initial induction period than solid state ion-exchanged materials. Tessonnier et al. [19] reported that catalysts prepared by direct vaporization-reaction of $\mathrm{MoO}_{3}$ displayed increased activity and limited deactivation. Reports also indicate that incorporation of ruthenium on Mo/HZSM5 catalysts improves catalyst performance [17, 20, 21].

The work reported here shows a comparison of the catalytic performance of Mo/HZSM5 and Ru-Mo/HZSM5 catalysts prepared by impregnation and vaporization-deposition and the results are interpreted in terms of catalyst characterization analyses.

\section{Experimental}

2.1. Catalyst Preparation. Four catalyst samples were prepared and labeled as follows: MV and RMV for Mo/HZSM5 and $\mathrm{Ru}-\mathrm{Mo} / \mathrm{HZSM} 5$ samples prepared by vaporization-deposition of $\mathrm{MoO}_{3}$ and $\mathrm{MI}$ and RMI for Mo/HZSM5 and $\mathrm{Ru}-\mathrm{Mo} / \mathrm{HZSM} 5$ samples prepared by impregnation with $\left(\mathrm{NH}_{4}\right)_{6} \mathrm{Mo}_{7} \mathrm{O}_{24} \cdot 4 \mathrm{H}_{2} \mathrm{O}$. Materials and reagents used were HZSM5 zeolite ( $\mathrm{Si} / \mathrm{Al}=15, \mathrm{CBV} 3020 \mathrm{E}$, Zeolyst International, PA), $\mathrm{MoO}_{3}$ (99.95\%, Alfa Aesar), $\left(\mathrm{NH}_{4}\right)_{6} \mathrm{Mo}_{7} \mathrm{O}_{24} \cdot 4 \mathrm{H}_{2} \mathrm{O}$ 
(99.98\%, Sigma-Aldrich), and $\mathrm{RuCl}_{3}$ (99.98\%, Sigma-Aldrich).

For the two samples prepared by vaporization-deposition of $\mathrm{MoO}_{3}$, dried $\mathrm{MoO}_{3}$, measured to contain a final Mo load of $4.0 \mathrm{wt} \%$, was added to a small amount of nanopure water in a beaker. For the sample containing $\mathrm{Ru}(\mathrm{RMV})$, dried $\mathrm{RuCl}_{3}$, measured to contain a final Ru load of $0.5 \mathrm{wt} \%$, was also added to the beaker. Next, the content of the beaker was sonicated until complete dispersion. After that, dried HZSM5 zeolite was added to the beaker to obtain a paste. This mixture was dried overnight at room temperature and then for 2 hours at $100^{\circ} \mathrm{C}$. The solid obtained was crushed and calcined under flowing air (UHP, Norco Inc., ID) in a straight quartz tube reactor placed in a split furnace (Mellen). The temperature was increased from room temperature to $700^{\circ} \mathrm{C}$ in 2 hours and maintained at $700^{\circ} \mathrm{C}$ for 30 minutes. Finally, the powder obtained was crushed, pressed, and sieved to obtain particles in the 40-60 mesh range.

For preparing $\mathrm{MI}$ and $\mathrm{RMI},\left(\mathrm{NH}_{4}\right)_{6} \mathrm{Mo}_{7} \mathrm{O}_{24} \cdot 4 \mathrm{H}_{2} \mathrm{O}$ was dissolved (along with dried $\mathrm{RuCl}_{3}$ for the case of RMI) in a minimal amount of water and added to the dried zeolite. Next, the impregnated material was dried, calcined, crushed, and sieved as for the case of MV and RMV.

For comparison, a blank sample was prepared using only zeolite that was mixed with similar amount of water as used for the actual catalyst samples, dried, and calcined at $700^{\circ} \mathrm{C}$ for 30 minutes.

2.2. Catalyst Reaction Studies. Reaction studies were performed in a U-tube quartz reactor heated by an electric furnace (Carbolite) as shown in Figure 1. Only one experiment was performed at each reaction condition. Catalyst samples in the 40-60 mesh range were loaded in the reactor and a mixture of $20 \mathrm{sccm} \mathrm{CH}_{4}$ (Scott Specialty Gases, Inc., PA) and $50 \mathrm{sccm} \mathrm{N}_{2}$ (UHP, Norco Inc., ID) was flowed through the catalyst bed at a total gas hourly space velocity of $8,400 \mathrm{sccm} /$ (gram catalyst $\times$ hour). The catalyst bed temperature was ramped at $10^{\circ} \mathrm{C} / \mathrm{min}$ to reaction temperature (i.e., either 600 or $700^{\circ} \mathrm{C}$ ) and then maintained at reaction temperature for 6 hours. The gaseous stream exiting the reactor was analyzed by gas chromatography on an SRI Multiple Gas Analyzer \#2 GC equipped with an MS13X packed column and a TCD detector and a 60MXT1 capillary column and FID detector. The lines between the reactor and the GC inlet were heat-traced and maintained at $120^{\circ} \mathrm{C}$.

After 6 hours of reaction time, the flow of $\mathrm{CH}_{4}$ was stopped. The catalyst bed was maintained at reaction temperature for an additional hour under flowing nitrogen and then allowed to cool down to room temperature. The spent catalyst sample was recovered for further analyses.

2.3. Catalyst Characterization. Nitrogen physisorption isotherms at liquid nitrogen temperatures were measured on a Quantachrome Autosorb 1-C instrument. Samples were outgassed at $105^{\circ} \mathrm{C}$ for four hours prior to the analysis. Isotherms points in the $\mathrm{P} / \mathrm{P}_{0}=0.05-0.10$ range were used to calculate the BET. surface area (SA) [22]. Micropore volume (MPV) was estimated by the $t$-method [23].

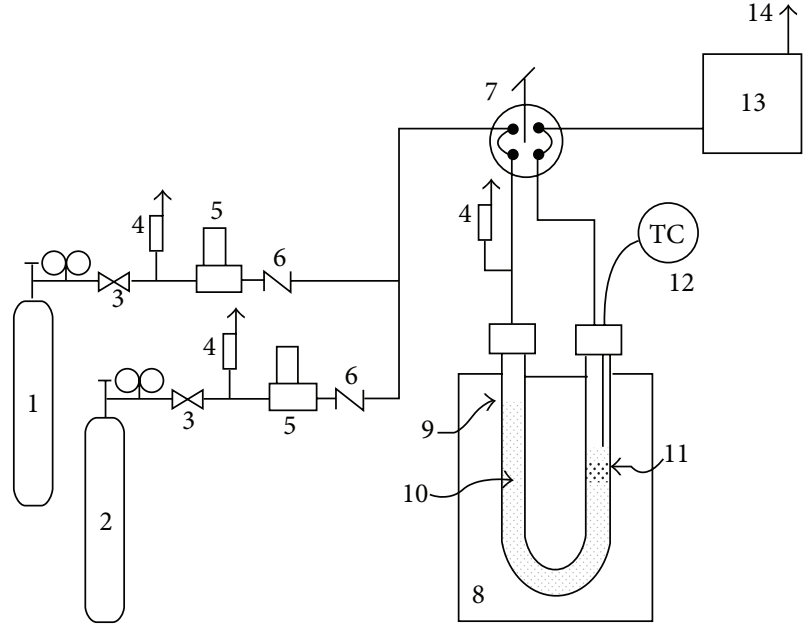

FIGURE 1: Outline of the experimental setup (not to scale). (1) Methane, (2) nitrogen, (3) on-off valve, (4) pressure relief valve, (5) mass-flow controller, (6) one-way check valve, (7) switching valve, (8) furnace, (9) reactor, (10) inert material as preheating bed, (11) catalyst, (12) thermocouple, (13) gas chromatograph, and (14) vent to laboratory hood.

Temperature-programmed reduction (TPR) analyses were performed on a Pyris/Diamond TG/DTA thermogravimetric analyzer under $100 \mathrm{sccm}$ of flowing mixture of $5 \% \mathrm{v} / \mathrm{v}$ hydrogen in helium (certified, Norco Inc., Idaho). About $12.5 \mathrm{mg}$ of sample was loaded in the thermogravimetric analyzer pan, dried at $100^{\circ} \mathrm{C}$ for $30 \mathrm{~min}$, and heated at $15^{\circ} \mathrm{C} / \mathrm{min}$ from 100 to $900^{\circ} \mathrm{C}$. The derivative of the weight change with time as a function of sample temperature was used to report the TPR profiles. The curves are displayed offset for clarity.

Temperature-programmed oxidation (TPO) of coke deposited on spent catalyst samples was performed in a similar manner as the TPR analyses. The only two differences were the use of flowing air (hydrocarbon free, Norco Inc., Idaho) instead of the hydrogen/helium mixture and heating to $700^{\circ} \mathrm{C}$ instead of $900^{\circ} \mathrm{C}$. Weight differences between 100 and $700^{\circ} \mathrm{C}$ were measured directly and corrected for the weight increase expected for oxidation of Mo and Ru in the samples.

\section{Results and Discussion}

Reaction testing experiments showed formation of hydrogen, ethylene, propylene, benzene, toluene, and xylenes. A summary of hydrocarbon apparent production rates at $3 \mathrm{~h}$ and $6 \mathrm{~h}$ TOS is shown in Figure 2. A wealth of information becomes apparent from this figure: (i) for any given catalyst, higher reaction rates were obtained at the higher temperature as expected, (ii) catalysts prepared by impregnation showed higher activity, with total production rates approximately three to six times higher than catalysts prepared by vaporization-deposition, (iii) catalysts prepared by impregnation showed higher selectivity to aromatics (lower selectivity to ethylene) in comparison to catalysts prepared by vaporization deposition, (iv) all catalysts were deactivated, 
TABLE 1: Nitrogen physisorption results.

\begin{tabular}{lcccccc}
\hline \multirow{2}{*}{ Samples } & \multicolumn{2}{c}{ Fresh } & \multicolumn{2}{c}{ Spent at $600^{\circ} \mathrm{C}$} & \multicolumn{2}{c}{ Spent at $700^{\circ} \mathrm{C}$} \\
& $\mathrm{SA}\left[\mathrm{m}^{2} / \mathrm{g}\right]$ & $\mathrm{MPV}[\mathrm{cc} / \mathrm{g}]$ & $\mathrm{SA}\left[\mathrm{m}^{2} / \mathrm{g}\right]$ & $\mathrm{MPV}[\mathrm{cc} / \mathrm{g}]$ & $\mathrm{SA}\left[\mathrm{m}^{2} / \mathrm{g}\right]$ & $\mathrm{MPV}[\mathrm{cc} / \mathrm{g}]$ \\
\hline Original zeolite & 403 & 0.12 & & & & \\
MV & 197 & 0.05 & 203 & 0.05 & 199 & 0.05 \\
MI & 327 & 0.10 & 290 & 0.08 & 275 & 0.08 \\
RMV & 175 & 0.05 & 194 & 0.05 & 161 & 0.04 \\
RMI & 221 & 0.06 & 252 & 0.07 & 227 & 0.06 \\
\hline
\end{tabular}

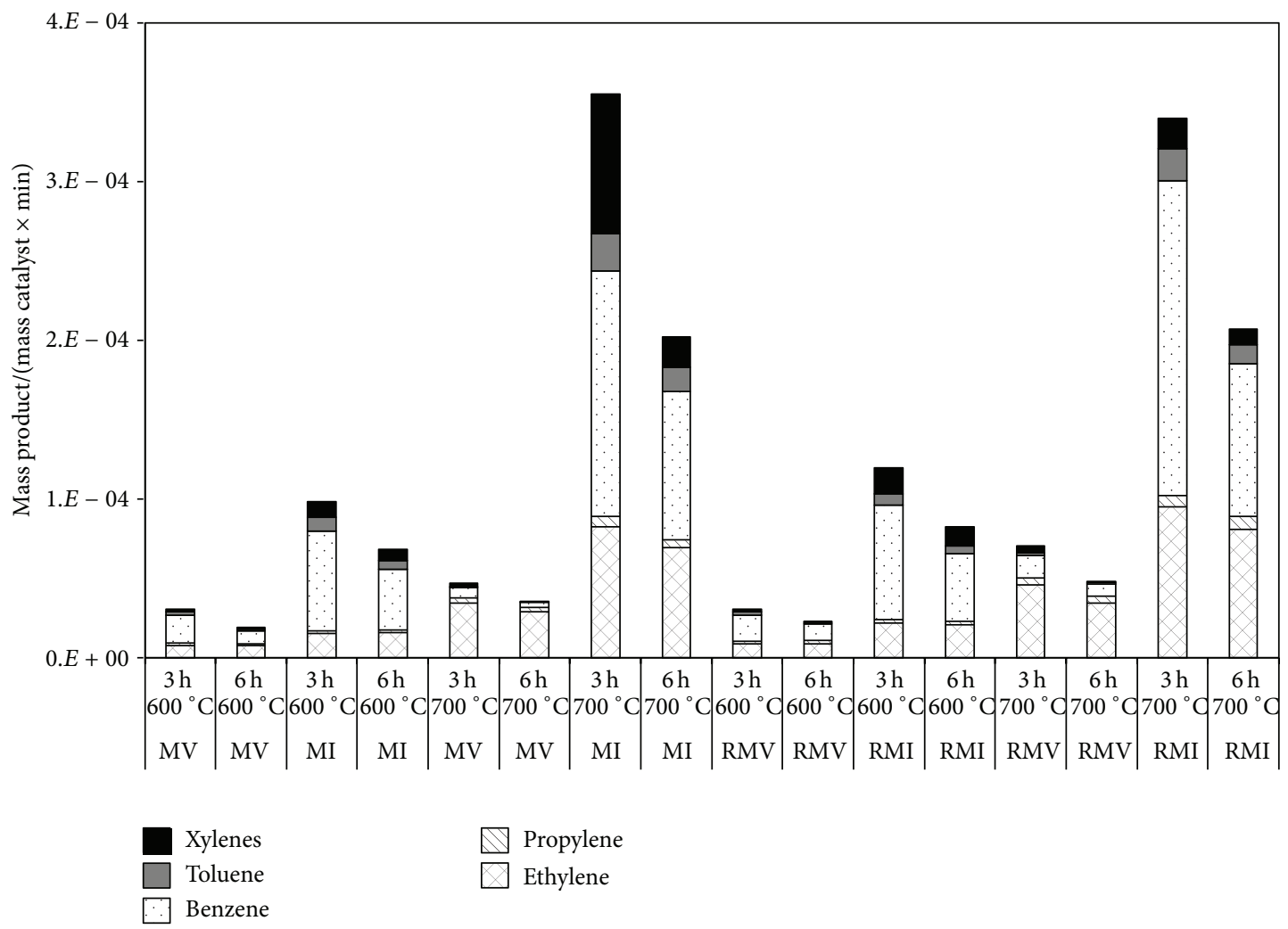

FIGURE 2: Summary of hydrocarbon instantaneous apparent production rates. Catalysts, reaction temperatures, and times on stream as indicated.

and (v) ethylene production rates were less affected by catalyst deactivation than aromatics production rates.

Nitrogen physisorption analyses are shown in Table 1. The original zeolite sample had a BET surface area (SA) of $403 \mathrm{~m}^{2} / \mathrm{g}$ and micropore volume (MPV) of $0.12 \mathrm{cc} / \mathrm{g}$. Once the Mo or $\mathrm{Ru}+\mathrm{Mo}$ components were added, the porosity of the samples became lower. Lower SA and MPV after incorporation of Mo have been reported previously [24]. This decrease in porosity was more marked in the case of vaporization-deposition than in the case of impregnation. For a given preparation method, the sample that contained $\mathrm{Ru}$ showed a more marked decrease in porosity as well. This change is indicating that Mo- and Ru-containing species blocked a fraction of zeolite microporosity. Table 1 also shows that the porosity of the samples did not change much due to use.
The presence of carbonaceous residues on the spent samples was studied by TPO using a thermogravimetric analyzer. The curves obtained are shown in Figure 3. This figure shows that the oxidation of carbonaceous residues produced TPO peaks around 425 and $468^{\circ} \mathrm{C}$ for samples used at 600 and $700^{\circ} \mathrm{C}$, respectively. MI and RMI samples used at $700^{\circ} \mathrm{C}$ showed tails at temperatures higher than $500^{\circ} \mathrm{C}$. For the particular case of MI, temperatures higher than $600^{\circ} \mathrm{C}$ were required to complete the oxidation of carbonaceous residues.

From TPO weight differences between 100 and $700^{\circ} \mathrm{C}$, the total amount of carbonaceous residues may be estimated. However, TPO conditions were expected to oxidize not only carbonaceous residues but also the carbided molybdenum usually proposed as the active Mo species $[25,26]$ and the ruthenium component. In other words, weight reductions 


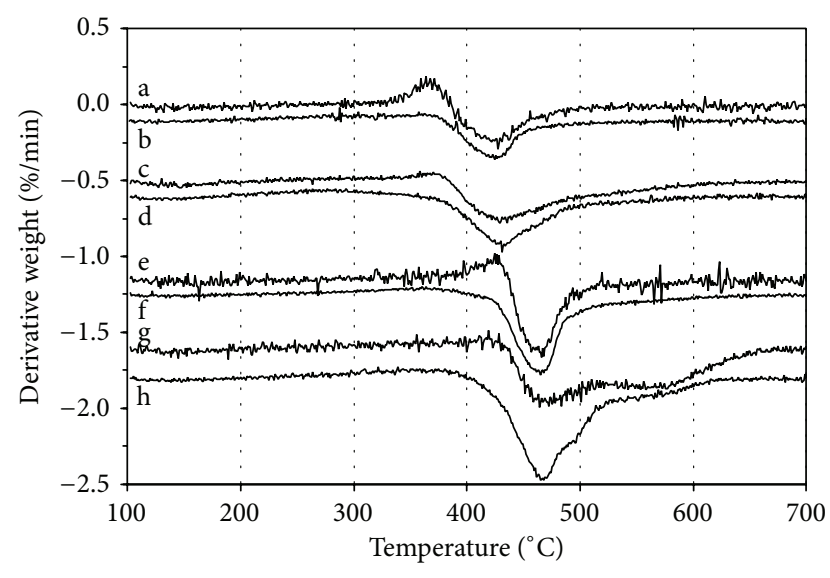

FIGURE 3: Temperature-programmed oxidation of carbonaceous residues on (a) $\mathrm{MV} 600^{\circ} \mathrm{C}$, (b) $\mathrm{RMV} 600^{\circ} \mathrm{C}$, (c) MI $600^{\circ} \mathrm{C}$, (d) RMI $600^{\circ} \mathrm{C}$, (e) $\mathrm{MV} 700^{\circ} \mathrm{C}$, (f) $\mathrm{RMV} 700^{\circ} \mathrm{C}$, (g) MI $700^{\circ} \mathrm{C}$, and (h) RMI $700^{\circ} \mathrm{C}$.

are expected from the oxidation of carbonaceous residues, but weight increases are expected from the oxidation of carbided molybdenum or ruthenium. In fact, sample MV produced weight gains around 366 and $427^{\circ} \mathrm{C}$, respectively (see Figure 3, curves a and e). These weight gains may be related to the aforementioned oxidation of carbided molybdenum. Considering that the samples in this study contained $4 \mathrm{wt} \%$ of $\mathrm{Mo}$, which becomes $\mathrm{Mo}_{2} \mathrm{C}$ in the early stages of the reaction experiment and produces $\mathrm{MoO}_{3}$ in the TPO analysis, the percent weight increase expected in the TPO analysis would be $1.7 \mathrm{wt} \%$. Similarly, for samples RMV and RMI, which also contain $0.5 \mathrm{wt} \% \mathrm{Ru}$ in addition to $4 \mathrm{wt} \%$ Mo, the expected weight increase would be $1.9 \mathrm{wt} \%$. Then, to estimate the total amount of carbonaceous residues shown in Table 2, the total weight change between 100 and $700^{\circ} \mathrm{C}$ was adjusted by $1.7 \mathrm{wt} \%$ in MV and MI samples and by $1.9 \mathrm{wt} \%$ in RMV and RMI samples.

Table 2 shows that spent samples contained carbonaceous deposits ranging from 2.5 to $6.0 \mathrm{wt} \%$ and that higher amounts were found in catalysts used at the higher temperature and in catalysts prepared by impregnation. The fact that spent samples had surface areas similar to fresh ones is indicating that pore blockage was not the main cause for catalyst deactivation. Therefore, the most likely reason was coverage of active sites by carbonaceous residues.

The experimental protocol applied in this work did not allow for continuous measurement of carbonaceous residue deposition. Thus, Figure 2 is not showing the production of carbonaceous residues. However, once the total amount of carbonaceous residues is known from TPO analyses, it can be compared with the total (integrated) amount of products exiting the reactor. Figure 4 was constructed for this purpose. For this figure, the integrated amounts of hydrocarbon products exiting the reactor (i.e., ethylene, propylene, benzene, toluene, and xylenes) were calculated by integrating, over the six hours that the experiments lasted, using instantaneous production rates calculated from GC
TABLE 2: Carbonaceous residues measured by TPO.

\begin{tabular}{lcccccccc}
\hline Sample & \multicolumn{2}{c}{ MV } & \multicolumn{2}{c}{ MI } & \multicolumn{2}{c}{ RMV } & \multicolumn{2}{c}{ RMI } \\
\hline Spent at $\left({ }^{\circ} \mathrm{C}\right)$ & 600 & 700 & 600 & 700 & 600 & 700 & 600 & 700 \\
Carbon deposits [wt\%] & 2.5 & 3.3 & 3.7 & 5.5 & 2.7 & 4.1 & 3.8 & 6.0 \\
\hline
\end{tabular}

TABLE 3: Weight loss within the $300-900^{\circ} \mathrm{C}$ range during temperature-programmed reduction.

\begin{tabular}{lcccc}
\hline Sample & MV & RMV & MI & RMI \\
\hline Weight loss (wt\%) & 1.2 & 1.4 & 0.9 & 1.3 \\
\hline
\end{tabular}

analyses at different times on stream. Carbonaceous residues were assumed to consist of elemental carbon. Figure 4(a) shows that, from an integrated point of view, the catalysts containing $\mathrm{Ru}$ were more active. Figure 4(b) shows that the selectivity to hydrocarbon products exiting the reactor was higher (i) on catalysts prepared by impregnation, (ii) on catalysts containing $\mathrm{Ru}$, and (iii) at $700^{\circ} \mathrm{C}$ than at $600^{\circ} \mathrm{C}$. Figure 4 also shows that only between $24 \%$ (case of MV at $600^{\circ} \mathrm{C}$ ) and $72 \%$ (case of RMI at $700^{\circ} \mathrm{C}$ ) of the methane converted was transformed into hydrocarbon products that exited the reactor.

Temperature-programmed reduction curves are shown in Figure 5 and reduction weight losses are listed in Table 3. The weight loss within the $100-300^{\circ} \mathrm{C}$ temperature range in Figure 5 is assigned to water desorption. Sample MV (curve b) showed weight losses assigned to reduction phenomena starting around $600^{\circ} \mathrm{C}$ with relatively well-defined peaks at 670 and $765^{\circ} \mathrm{C}$. Sample RMV (curve c) showed reduction starting around $365^{\circ} \mathrm{C}$ and peaks around 407,615 , and $790^{\circ} \mathrm{C}$. Sample MI (curve d) showed reduction starting around $500^{\circ} \mathrm{C}$, a peak at $645^{\circ} \mathrm{C}$, and a less defined region at higher temperatures where reduction was still occurring. Finally, sample RMI (curve e) showed reduction starting around $310^{\circ} \mathrm{C}$ that continued at higher temperatures with less defined peaks at 500 and $735^{\circ} \mathrm{C}$.

The reduction of supported $\mathrm{MoO}_{3}$ species has been proposed to occur in two steps, that is, $\mathrm{MoO}_{3} \rightarrow \mathrm{MoO}_{2}$ and $\mathrm{MoO}_{2} \rightarrow \mathrm{Mo}$ [27]. The temperatures at which the two reduction steps occur give an indication of molybdenum dispersion. Higher reduction temperatures have been associated with larger molybdenum particles. In addition, broader peaks have been associated with stronger interaction with the support [27]. From Figure 5, it is apparent that the samples prepared by impregnation contained molybdenum more highly dispersed than the samples prepared by vaporization. Furthermore, one would expect weight losses of $2.0 \mathrm{wt} \%$ or $2.1 \mathrm{wt} \%$ for complete reduction of $\mathrm{Mo}$ or $\mathrm{Ru}+\mathrm{Mo}$ in $4 \mathrm{wt} \% \mathrm{Mo} / \mathrm{HZSM} 5$ and $0.5 \mathrm{wt} \% \mathrm{Ru}+4 \mathrm{wt} \% \mathrm{Mo} / \mathrm{HZSM} 5$ samples, respectively. Comparing these expected values to the actual results shown in Table 3 , it is clear that reduction was not complete. The higher difference between expected and measured weight losses was shown by samples prepared by impregnation. More incomplete reduction has been 


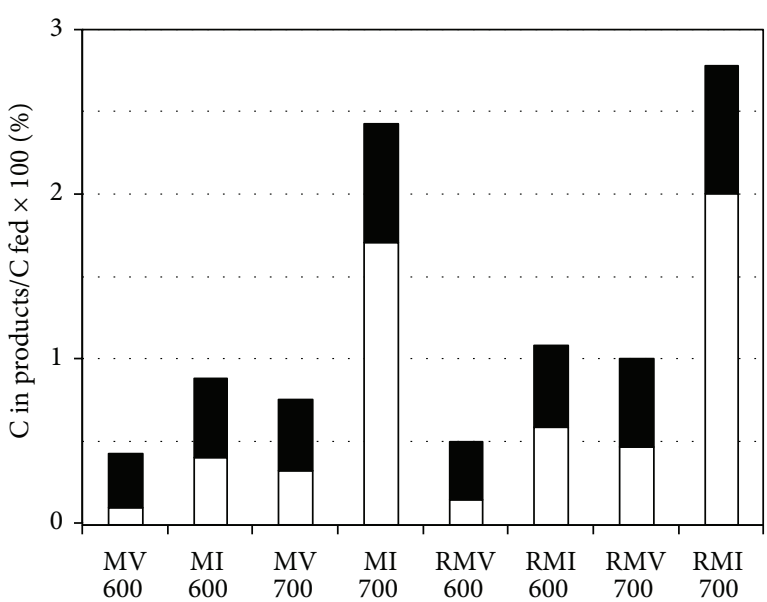

(a)

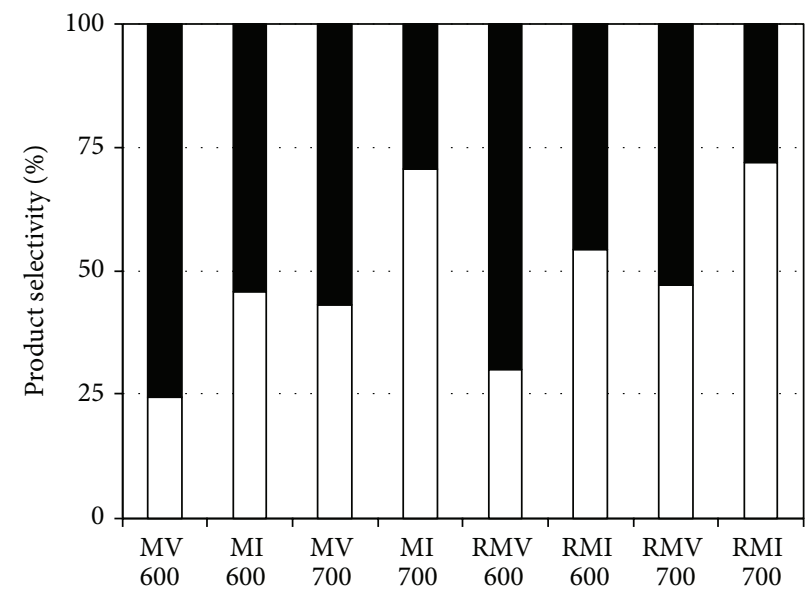

(b)

FIGURE 4: Two views of integrated catalyst selectivity to hydrocarbons leaving the catalyst (white) and carbonaceous residues remaining on the catalyst (black).

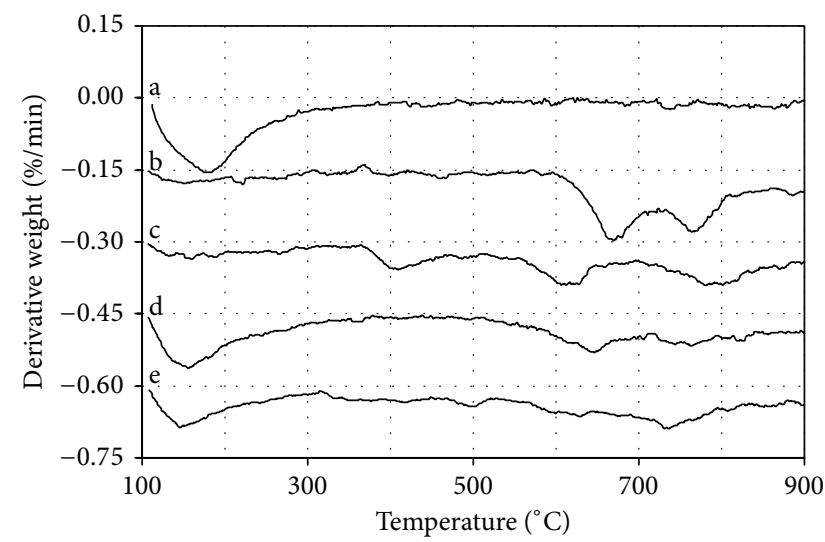

Figure 5: Temperature-programmed reduction of fresh (a) blank zeolite sample, (b) MV, (c) RMV, (d) MI, and (e) RMI samples.

associated with stronger interaction between Mo particles and supports [27]. Results in Table 3 also show that higher weight losses, associated with more complete reduction, were produced in the presence of $\mathrm{Ru}$. This result is in agreement with a previous report on the promoting effect of $\mathrm{Ru}$ on $\mathrm{Mo}$ reduction [16].

Ding and coworkers [28] have shown that higher selectivities to desired aromatics are related to active Mo species residing in the internal channels of the zeolite structure where spatial constraints inhibit chain-growth mechanisms that lead to carbon deposition. Therefore, the higher selectivity to aromatics displayed by the samples prepared by impregnation is an indication of a higher accessibility of the primary product (ethylene) to the acidic sites. However, this higher accessibility to acidic sites is not a consequence of higher surface area since sample RMI had a surface area only $12 \%$ higher than sample MV, whereas both activity and aromatics selectivity of the former were much higher. The better performance is likely a consequence of molybdenum being more dispersed and closer to acidic sites as TPR data suggest. With respect to the samples prepared by vaporization-deposition, their higher selectivity to carbon along with the lower interaction of Mo with acid sites found by TPR suggests that they may have contained an important fraction of $\mathrm{MoC}_{x}$ residing on the external surface of the catalyst.

\section{Conclusions}

Methane dehydroaromatization catalyst selectivity was studied on Mo/HZSM5 and Ru-Mo/HZSM5 catalyst samples prepared by two different methods: vaporization-deposition of $\mathrm{MoO}_{3}$ and impregnation with ammonium heptamolybdate. Vaporization-deposition rendered the catalyst more selective to ethylene and coke than the catalyst prepared by impregnation. This result is assigned to the formation of larger, more difficult to migrate into the zeolite channels, molybdenum oxide clusters when the vaporizationdeposition method was applied. An important fraction of these clusters may have remained on the external surface of the zeolite and away from internal acid sites. Once those clusters were carbided, they became the active sites for methane activation and production of intermediate ethylenelike fragments but were located too far from the internal zeolite acid sites for subsequent reactions. The eventual result was higher selectivity to coke and ethylene and less selectivity to desirable aromatic products. On the other hand, the ammonium heptamolybdate precursor likely produced smaller $\mathrm{MoO}_{3}$ clusters which migrated more easily into the zeolite channels during sample calcination. In this case, the ethylene-like fragments had a higher opportunity to react and produce desirable aromatics. Addition of ruthenium to the catalyst favored molybdenum dispersion and increased total product yields in both cases. 


\section{Conflict of Interests}

The authors declare that there is no conflict of interests regarding the publication of this paper.

\section{Acknowledgments}

This work was supported by the INL Laboratory-Directed Research and Development Program under DOE/NE Idaho Operations Office Contract DE-AC07-05ID14517. This paper has been authored by Battelle Energy Alliance, LLC, under Contract no. DE-AC07-05ID14517, with the U.S. Department of Energy. The United States Government and the publisher, by accepting the paper for publication, acknowledge that the United States Government retains a nonexclusive, paid-up, irrevocable, worldwide license to publish or reproduce the published form of this paper, or allow others to do so, for United States Government purposes.

\section{References}

[1] L. S. Wang, L. X. Tao, M. S. Xie, G. F. Xu, J. S. Huang, and Y. $\mathrm{D} . \mathrm{Xu}$, "Dehydrogenation and aromatization of methane under non-oxidizing conditions," Catalysis Letters, vol. 21, no. 1-2, pp. 35-41, 1993.

[2] H. Zheng, D. Ma, X. Bao et al., "Direct observation of the active center for methane dehydroaromatization using an ultrahigh field ${ }^{95}$ Mo NMR spectroscopy," Journal of the American Chemical Society, vol. 130, no. 12, pp. 3722-3723, 2008.

[3] Y. d. Xu, X. H. Bao, and L. W. Lin, "Direct conversion of methane under nonoxidative conditions," Journal of Catalysis, vol. 216, no. 1-2, pp. 386-395, 2003.

[4] Z. R. Ismagilov, E. V. Matus, and L. T. Tsikoza, "Direct conversion of methane on Mo/ZSM-5 catalysts to produce benzene and hydrogen: achievements and perspectives," Energy \& Environmental Science, vol. 1, no. 5, pp. 526-541, 2008.

[5] L. M. Petkovic and D. M. Ginosar, "Direct production of hydrogen and aromatics from methane or natural gas: review of recent U.S. patents," Recent Patents on Chemical Engineering, vol. 5, no. 1, pp. 2-10, 2012.

[6] D. Wang, J. H. Lunsford, and M. P. Rosynek, "Catalytic conversion of methane to benzene over Mo/ZSM-5," Topics in Catalysis, vol. 3, no. 3-4, pp. 289-297, 1996.

[7] A. Martínez, E. Peris, and G. Sastre, "Dehydroaromatization of methane under non-oxidative conditions over bifunctional Mo/ITQ-2 catalysts," Catalysis Today, vol. 107-108, pp. 676-684, 2005.

[8] V. I. Zaikovskii, A. V. Vosmerikov, V. F. Anufrienko et al., "Properties and deactivation of the active sites of an MoZSM5 catalyst for methane dehydroaromatization: Electron microscopic and EPR studies," Kinetics and Catalysis, vol. 47, no. 3, pp. 389-394, 2006

[9] A. K. Aboul-Gheit and A. E. Awadallah, "Effect of combining the metals of group VI supported on H-ZSM-5 zeolite as catalysts for non-oxidative conversion of natural gas to petrochemicals," Journal of Natural Gas Chemistry, vol. 18, no. 1, pp. 71-77, 2009.

[10] B. M. Weckhuysen, D. Wang, M. P. Rosynek, and J. H. Lunsford, "Conversion of methane to benzene over transition metal ion ZSM-5 zeolites-I. Catalytic characterization," Journal of Catalysis, vol. 175, no. 2, pp. 338-346, 1998.
[11] Y. Xu, W. Liu, S. Wong, L. Wang, and X. Guo, "Dehydrogenation and aromatization of methane in the absence of oxygen on Mo/HZSM-5 catalysts before and after $\mathrm{NH}_{4} \mathrm{OH}$ extraction," Catalysis Letters, vol. 40, no. 3-4, pp. 207-214, 1996.

[12] L. Y. Chen, L. W. Lin, Z. S. Xu, T. Zhang, and X. S. Li, "Promotional effect of Pt on non-oxidative methane transformation over Mo-HZSM-5 catalyst," Catalysis Letters, vol. 39, no. 3-4, pp. 169-172, 1996.

[13] F. Solymosi, J. Cserenyi, A. Szoke, T. Bansagi, and A. Oszko, "Aromatization of methane over supported and unsupported Mo-based catalysts," Journal of Catalysis, vol. 165, no. 2, pp. 150 161, 1997.

[14] D. J. Wang, J. H. Lunsford, and M. P. Rosynek, "Catalytic conversion of methane to benzene over Mo/ZSM-5," Topics in Catalysis, vol. 3, no. 3-4, pp. 289-297, 1996.

[15] H. Liu, X. Bao, and Y. Xu, "Methane dehydroaromatization under nonoxidative conditions over Mo/HZSM-5 catalysts: identification and preparation of the Mo active species," Journal of Catalysis, vol. 239, no. 2, pp. 441-450, 2006.

[16] Y. Y. Shu, Y. D. Xu, S. T. Wong, L. S. Wang, and X. X. Guo, "Promotional effect of Ru on the dehydrogenation and aromatization of methane in the absence of oxygen over Mo/HZSM-5 catalysts," Journal of Catalysis, vol. 170, no. 1, pp. 11-19, 1997.

[17] M. C. Iliuta, F. Larachi, B. P. A. Grandjean, I. Iliuta, and A. Sayari, "Methane nonoxidative aromatization over $\mathrm{Ru}-$ Mo/HZSM-5 in a membrane catalytic reactor," Industrial and Engineering Chemistry Research, vol. 41, no. 10, pp. 2371-2378, 2002.

[18] R. W. Borry III, Y. H. Kim, A. Huffsmith, J. A. Reimer, and E. Iglesia, "Structure and density of Mo and acid sites in Moexchanged $\mathrm{H}$-ZSM5 catalysts for nonoxidative methane conversion," Journal of Physical Chemistry B, vol. 103, no. 28, pp. 57875796, 1999.

[19] J. Tessonnier, B. Louis, M. Ledoux, and C. Pham-Huu, "Green catalysis for production of chemicals and CO-free hydrogen," Catalysis Communications, vol. 8, no. 11, pp. 1787-1792, 2007.

[20] M. C. Iliuta, B. P. A. Grandjean, and F. Larachi, "Methane nonoxidative aromatization over $\mathrm{Ru}-\mathrm{Mo} / \mathrm{HZSM}-5$ at temperatures up to $973 \mathrm{~K}$ in a palladium-silver/stainless steel membrane reactor," Industrial and Engineering Chemistry Research, vol. 42, no. 2, pp. 323-330, 2003.

[21] M. C. Iliuta, I. Iliuta, B. P. A. Grandjean, and F. Larachi, "Kinetics of methane nonoxidative aromatization over Ru-Mo/HZSM-5 catalyst," Industrial and Engineering Chemistry Research, vol. 42, no. 14, pp. 3203-3209, 2003.

[22] S. Brunauer, P. H. Emmett, and E. Teller, "Adsorption of gases in multimolecular layers," Journal of the American Chemical Society, vol. 60, no. 2, pp. 309-319, 1938.

[23] B. C. Lippens and J. H. Deboer, "Studies on pore systems in catalysts. V. The $t$ method," Journal of Catalysis, vol. 4, no. 3, pp. 319-323, 1965.

[24] H. Liu, W. Shen, X. Bao, and Y. Xu, "Methane dehydroaromatization over Mo/HZSM-5 catalysts: the reactivity of MoCx species formed from $\mathrm{MoOx}$ associated and non-associated with Brönsted acid sites," Applied Catalysis A, vol. 295, no. 1, pp. 7988, 2005.

[25] H. Liu, T. Li, B. Tian, and Y. Xu, "Study of the car-bonaceous deposits formed on a Mo/HZSM-5 catalyst in methane dehydro-aromatization by using TG and temperature-programmed techniques," Applied Catalysis A: General, vol. 213, no. 1, pp. 103-112, 2001. 
[26] J. P. Tessonnier, B. Louis, S. Rigolet, M. J. Ledoux, and C. PhamHuu, "Methane dehydro-aromatization on Mo/ZSM-5: about the hidden role of Brønsted acid sites," Applied Catalysis A: General, vol. 336, no. 1-2, pp. 79-88, 2008.

[27] J. R. Regalbuto and J. Ha, "A corrected procedure and consistent interpretation for temperature programmed reduction of supported $\mathrm{MoO}_{3}$," Catalysis Letters, vol. 29, no. 1-2, pp. 189-207, 1994.

[28] W. P. Ding, G. D. Meitzner, and E. Iglesia, "The effects of silanation of external acid sites on the structure and catalytic behavior of Mo/H-ZSM5," Journal of Catalysis, vol. 206, no. 1, pp. 14-22, 2002. 


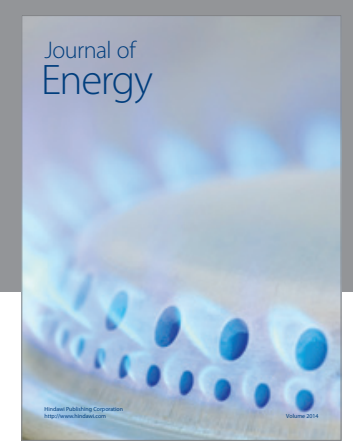

Journal of

Industrial Engineering
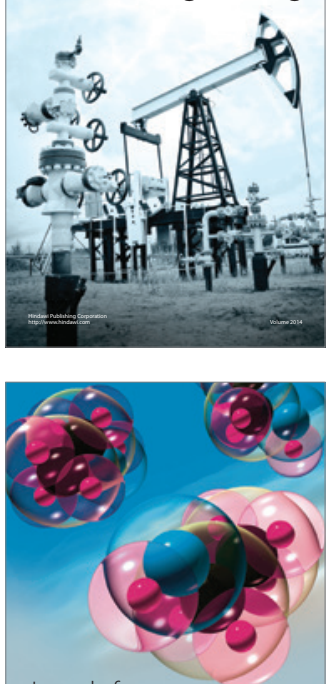

Fuels
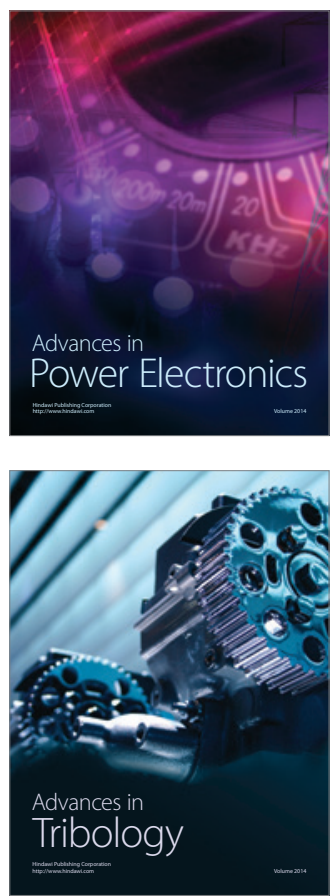

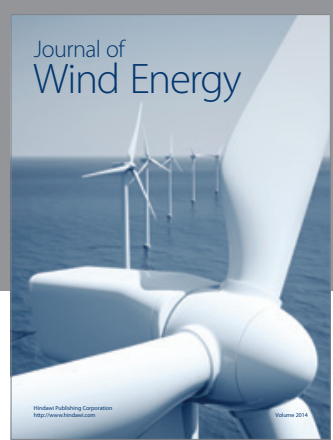

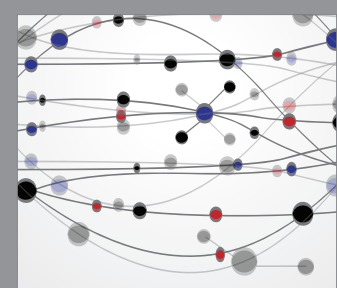

The Scientific World Journal

Submit your manuscripts at http://www.hindawi.com

Journal of

Structures
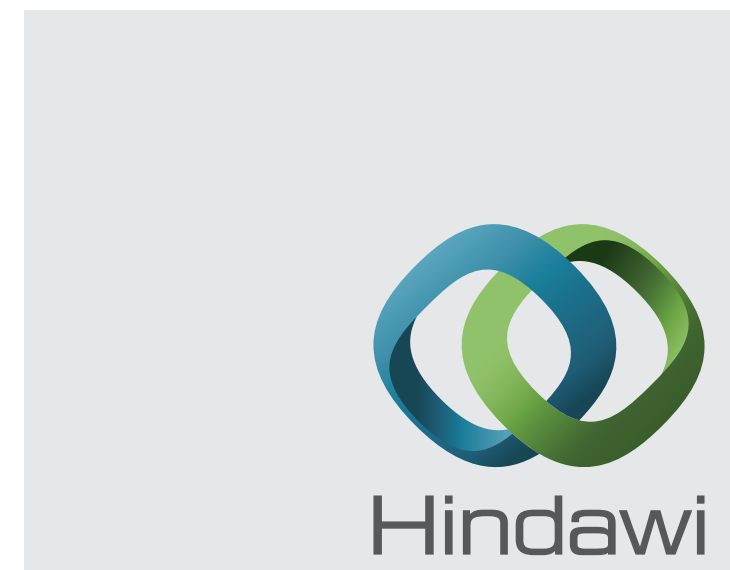

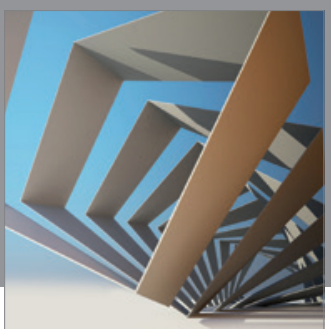

Rotating

Machinery
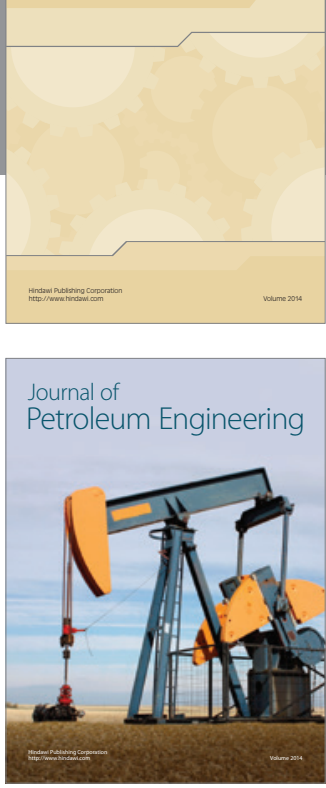

Journal of

Solar Energy
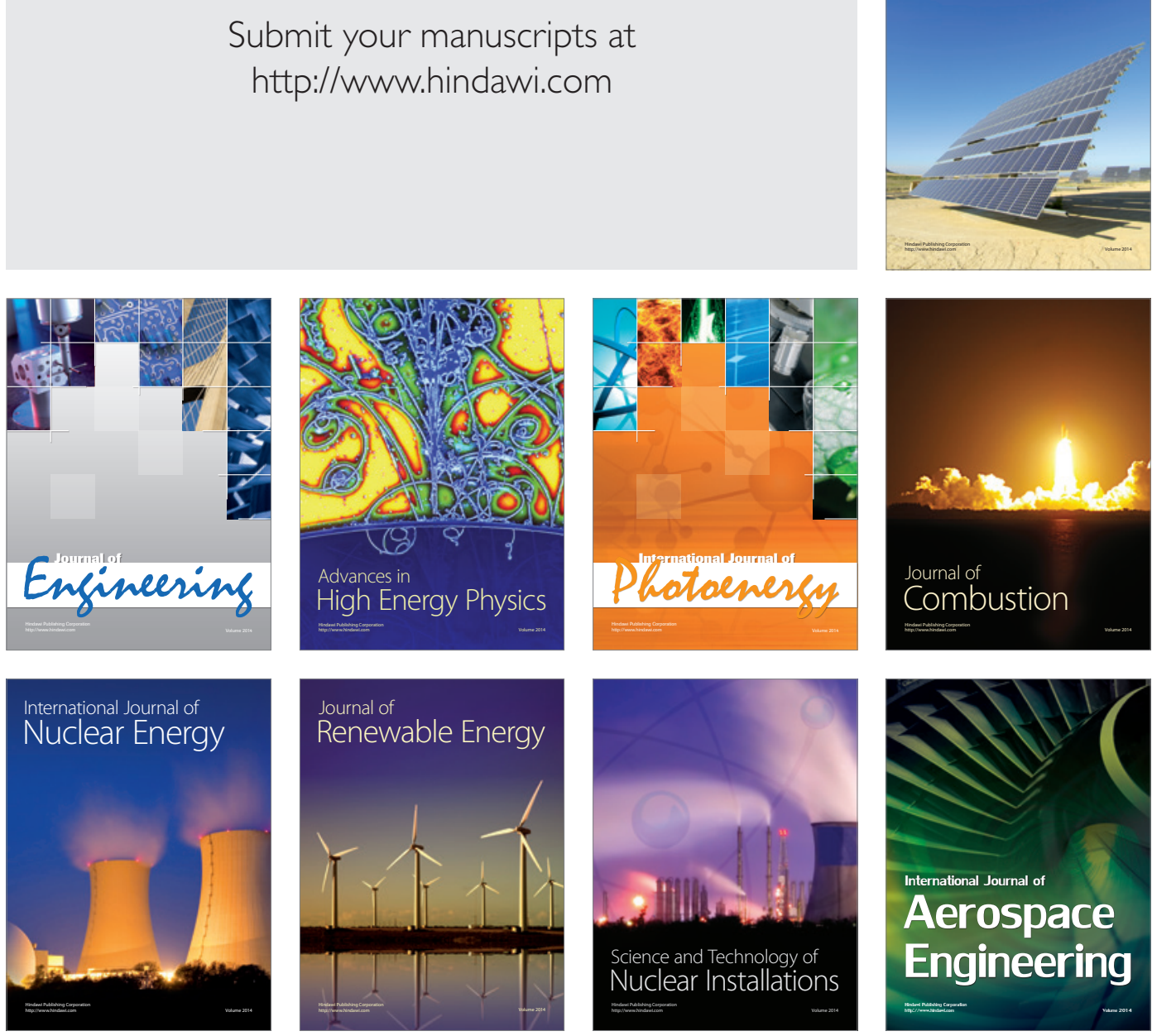